\title{
PERTUMBUHAN BIBIT KAKAO (Teobroma cacao L) DENGAN BERBAGAI PEMBERIAN DOSIS SERBUK GERGAJI PADA VARIETAS (BUNDO-F1) DI TANAH GAMBUT
}

\author{
Yoyon Riono ${ }^{1}$, \\ ${ }^{1}$ Jurusan Agroteknologi, Fakultas Pertanian, Universitas Islam Indragiri
}

Email: yoyonriono353@gmail.com

\begin{abstract}
This study aims to determine the growth of cacao seeds (Theobroma cacao L) with various doses of sawdust on Varieties (Bundo-F1) on peat lands. This research has been carried out in the experimental garden of the Faculty of Agriculture, Islamic University of Indragiri Tembilahan, Tembilahan Hulu Subdistrict, Indragiri Downstream District. When the study began from April to July 2019 this research was a field trial using a non-factorial randomized block design (RBD) consisting of 6 levels, namely $M 0=$ peat only, $M 1=1$ : 1 (sawdust: peat), M2 = $2: 1$ (sawdust: peat), M3 = 3: 1 (sawdust: peat). Each treatment was repeated three times to obtain 18 experimental trial plots in the field. Data from this study were analyzed using Analysis of Variance (ANOVA). The results showed that the treatment of M2 = $2: 1$ (sawdust: peat) could have a significant effect on plant height $(\mathrm{cm})$, stem diameter $(\mathrm{mm})$, number of leaves (strands),
\end{abstract}

Keywords: Cocoa, Sawdust, Peat

\begin{abstract}
Abstrak
Penelitian ini bertujuan untuk mengetahui pertumbuhan bibit Kakao (Teobroma cacao L) dengan berbagai pemberian dosis serbuk gergaji pada Vairietas ( Bundo-F1) ditanah gambut. Penelitian ini telah dilaksanakan di kebun percobaan fakultas pertanian universitas islam indragiri tembilahan, kecamatan tembilahan hulu, kabupaten indragiri hilir. Waktu penelitian di mulai dari bulan april sampai juli 2019 penelitian ini merupakan percobaan lapangan menggunakan metpde rancangan acak kelompok (RAK) nonfaktorial yang terdiri dari 6 taraf yaitu $\mathrm{M0}=$ gambut saja, $\mathrm{M} 1=1: 1$ (serbuk gergaji:gambut), $\mathrm{M} 2=2: 1$ (serbuk gergaji: gambut), M3 = 3:1(serbuk gergaji:gambut). Setiap perlakuan diulang tiga kali sehingga diperoleh 18 petak-petak percobaan perlakuan dilapangan. Data hasil penelitian ini dianalisis dengan menggunakan Analysis Of Variance (ANOVA). Hasil penelitian menunjukan bahwa dengan perlakuan $M 2=2: 1$ (serbuk gergaji:gambut) dapat memberikan pengaruh nyata terhadap tinggi tanaman $(\mathrm{cm})$, diameter batang $(\mathrm{mm})$, jumlah daun(helai),
\end{abstract}

Kata kunci: Kakao, Serbuk Gergaji, Gambut

\section{PENDAHULUAN}

Salah satu komoditas perkebunan yang sangat penting dalam menyumbang perolehan devisa negara adalah kakao. Selama tahun 2000 jumlah ekspor kakao sebesar 424.088 ton, sedangkan pada tahun 2001 ekspor kakao Indonesia sedikit menurun yaitu sebesar 393.224 ton dengan nilai US\$ 391.086.033 (BPS 2002). ITC (2001) melaporkan bahwa pada tahun 1999/2000, Indonesia merupakan produsen kakao ketiga dunia dengan pangsa $14 \%$. Posisi pertama ditempati Cote d'Ivoire (Pantai Gading) $44 \%$, dan menyusul Ghana $15 \%$
Selain untuk konsumsi dalam negeri terutama untuk industri kosmetik, farmasi dan industri makanan, komoditi kakao juga merupakan komoditas ekspor. Ekspor kakao terbesar adalah dalam bentuk biji kering (cacao beans). Tujuan utama ekspor kakao Indonesia adalah Amerika Serikat sekitar $40 \%$ dari total ekspor, Singapura $17 \%$, Malaysia $14 \%$, Brazil $8 \%$ dan Cina 5\% (Haryadi 2005). Penurunan jumlah ekspor kakao Indonesia salah satunya karena mutu biji kakao yang sangat rendah, akibatnya diberlakukan automatic detention yang akan berpengaruh terhadap harga jual. 
Berdasarkan kelompok komoditi pangan yang mengalami penahanan dari FDA pada periode Januari hingga Juni 2000, kakao menempati urutan kedua yaitu sebesar $22 \%$ setelah udang beku (Raharjo 2001). Biji kakao Indonesia mempunyai kelemahan dalam hal kurang terfermentasi, tidak cukup kering, ukuran biji yang tidak seragam, kadar asam lemak rendah, citarasa yang beragam dan tidak konsisten dari segi mutu (Sigg dan Effendi 1989), serta derajat keasaman biji kakao Indonesia cenderung masih tinggi, yaitu kurang dari 5.

Pemupukan yang tepat dapat menghasilkan panen yang optimal dan laba yang maksimal. jika tidak tepat dapat mengakibatkan gagal panen atau menurunya produktivitas yang mengakibatkan kerugian, selain pupuk keberhasilan budidaya tanaman adalah mempersiapkan media tanam yang sesuai bagi pertumbuhan dan perkembangan tanaman. Media yang alami terdiri atas campuran tanah dan bahan-bahan organik yang memiliki kandungan hara yang tinggi. ketersediaan air dalam media tanam harus mencukupi atau tingkat kelembaban relatif lebih tinggi dari areal tanam biasa.

Lahan gambut di Indonesia memiliki luas sekitar 16,5 sampai 27 juta ha dan tersebar di daerah rawa belakang pantai Sumatra, Kalimantan dan Papua serta terdapat kelompok kecil di Sulawesi, Jawa dan Kepulawan Maluku (Hardjowigeno, 1989). Luas lahan gambut Riau adalah 4.043.060,2 hektar dan terdapat hampir disemua wilayah Kabupaten, tetapi yang paling luas terdapat di wilayah kabupaten yang berada di pantai timur. Enam kabupaten yang memiliki lahan gambut paling luas berturut-turut adalah Kabupaten Indragiri Hilir (983 ribu ha atau $24,3 \%$ dari total lahan provinsi), Bengkalis (856 ribu ha atau 21,2\% ), Pelalawan (680 ribu ha atau $16,8 \%$ ), Siak (504 ribu ha atau $12,5 \%)$, Rokan Hilir (454 ribu ha atau $11,2 \%)$, dan Indragiri Hulu (222 ribu ha atau 5,5\%). Kabupaten lain seperti Kampar, Karimun, dan Pekan baru hanya memilikilahan gambut kurang dari 5\% (Wahyunto dan B. Heryanto, 2005). Walaupun tanah gambut mempunyai potensi dari sisi luas lahan, akan tetapi tanah gambut merupakan tanah yang bermasalah.

Permasalahan yang terjadi pada pertanian di tanah gambut adalah kemasaman tanah yang relatif tinggi dengan kisaran $\mathrm{pH}$ 3-4 dan keracunan Al,Fe dan Mn dan rendahnya unsur hara terutama N,P dan K (Agus dan Subiksa, 2008). Sehingga untuk melakukan budidaya tanaman di tanah gambut perlu dilakukan penambahan pupuk anorganik $\mathrm{N}, \mathrm{P}$, dan $\mathrm{K}$ agar dapat memenuhi kebutuhan unsur hara yang di butuhkan oleh tanaman. Namun demikian penggunaan pupuk anorganik sintetis secara terus menerus dapat mengakibatkan kesuburan tanah menurun (Husnain et al., 2005). Penggunaan pupuk N, $P$, dan $K$ anorganik secara terus-menerus dengan takaran tinggi tanpa pengembalian sisa panen akan mempercepat pengurasan hara lain seperti $\mathrm{S}, \mathrm{Ca}, \mathrm{Mg}$ serta unsur mikro $\mathrm{Zn}$ dan $\mathrm{Cu}$ jarang ditambahkan ke dalam tanah (Las et al., 2006). Untuk itu perlu ditambahkan pupuk organik.

Berdasarkan uraian permasalahan diatas maka penulis tertarik melakukan penelitian dengan judul" pertumbuhan bibit Kakao (Teobroma cacao L) dengan berbagai pemberian dosis serbuk gergaji pada Vairietas ( Bundo-F1) ditanah gambut"

\section{TINJAUAN PUSTAKA}

Tanaman kakao (Theobroma cacao), termasuk dalam famili Sterculiaceae yang merupakan tanaman asli Amerika utara, namun sekarang tanaman kakao telah dibudi dayakan di daerah tropis. Tinggi tanaman kakao berkisar antara 4-8 m. Biji kakao ini diolah menjadi coklat. Klasifikasi kakao terdiri dari:

Kingdom : Plantae

divisi : Magnoliophyta

kelas : Magnoliopsida

ordo : Malvales

famili : Stercul iaceae

genus : Theobroma

spesies : Theobroma cacao (Minifie 1999).

\subsection{Buah}

Buah kakao berbentuk lonjong dengan panjang 15-30 cm dan lebar $8-10 \mathrm{~cm}$, buah yang matang berwarna kuning-oranye dengan berat sekitar $500 \mathrm{~g}$ ketika matang. Polong buah kakao mengandung 20-60 biji terletak dalam pulp yang berwarna putih. Setiap butir biji kakao mengandung lemak sekitar 40-50 \%. Biji kakao mengandung komponen aktif yaitu theobromin, yang merupakan suatu komponen senyawa yang mirip dengan kafein (Sunanto 1992).

Tanaman kakao (Theobroma cacao L.) termasuk tanaman tahunan yang tergolong dalam kelompok tanaman caulofloris, yaitu tanaman yang berbunga dan berbuah pada batang dan cabang. Tanaman ini pada garis besarnya dapat dibagi atas dua bagian, yaitu bagian vegetatif yang meliputi akar, batang, daun dan bagian generatif yang meliputi bunga dan buah (Lukito dkk, 2010). Habitat asli tanaman kakao adalah hutan tropis dengan naungan pohon-pohon yang tinggi, curah hujan tinggi, suhu sepanjang tahun 
relatif sama, serta kelembaban tinggi yang relatif tetap. Dalam habitat seperti itu, tanaman kakao akan tumbuh tinggi tetapi bunga dan buahnya sedikit. Jika dibudidayakan di kebun, tinggi tanaman umur tiga tahun mencapai 1,8 - 3,0 meter dan pada umur 12 tahun dapat mencapai 4,50 - 7,0 meter. Tinggi tanaman tersebut beragam, dipengaruhi oleh intensitas naungan serta faktor-faktor tumbuh yang tersedia. Tanaman kakao bersifat dimorfisme, artinya mempunyai dua bentuk tunas vegetatif. Tunas yang arah pertumbuhannya ke atas disebut dengan tunas ortotrop atau tunas air (wiwilan atau chupon), sedangkan tunas yang arah pertumbuhannya ke samping disebut dengan plagiotrop (cabang kipas atau fan) (Pusat Penelitian dan Pengembangan Perkebunan, 2010 ).

Tanaman kakao asal biji, setelah mencapai tinggi 0,9-1,5 meter akan berhenti tumbuh dan membentuk jorket (jorquette). Jorket adalah tempat percabangan dari pola percabangan ortotrop ke plagiotrop dan khas hanya pada tanaman kakao. Pembentukan jorket didahului dengan berhentinya pertumbuhan tunas ortotrop karena ruasruasnya tidak memanjang. Pada ujung tunas tersebut, stipula (semacam sisik pada kuncup bunga) dan kuncup ketiak daun serta tunas daun tidak berkembang. Dari ujung perhentian tersebut selanjutnya tumbuh $3-6$ cabang yang arah pertumbuhannya condong ke samping membentuk sudut $0-60^{\circ}$ dengan arah horisontal. Cabang-cabang itu disebut dengan cabang primer (cabang plagiotrop). Pada cabang primer tersebut kemudian tumbuh cabang-cabang lateral (fan) sehingga tanaman membentuk tajuk yang rimbun (Pusat Penelitian dan Pengembangan Perkebunan, 2010).

\subsection{Daun}

Karateristik tanaman kakao diantaranya meliputi batang, cabang, daun, bunga, buah, biji, dan akar. Warna batang coklat tua kehitaman, alur pada kulit batang utama teratur dan rapi, sedangkan alur pada cabang kurang tegas. Permukaan batang utama kasar, alurnya berwarna agak keputihan. Bentuk daun ujungnya runcing, ada penyempitan pada pangkalnya (bottle neck) warna daun hijau tua tegas, sedangkan daun muda merah. (Pusat Penelitian Kopi dan Kakao Indonesia 2005). Indeks luas daun (ILD) adalah besarnya angka perbandingan antara total luas permukaan seluruh daun yang ada pada tajuk dengan luas bidang tanah yang dinauni tajuk tersebut. Pada tingkat perkembangan awal, pertumbuhan dan leba daun akan terus bertambah sejalan bertambahnya umur tanaman. Dengan demikian luas daun pada tajuk akan bertambah, demikian pula luas tanah yang dilindungi jga meningkat. Peningkatan luas daun cenderung mengakibatkan daun saling menutupi antara yang satu dengan yang lainnya (Suwarto dan Octaviany, 2011).

Tangkai daun bentuknya silinder dan bersisik halus, bergantung pada tipenya. Salah satu sifat khusus daun kakao yaitu adanya dua persendian (articulation) yang terletak di pangkal dan ujung tangkai daun. Dengan persendian ini dilaporkan daun mampu membuat gerakan untuk menyesuaikan dengan arah datangnya sinar matahari. Bentuk helai daun bulat memanjang (oblongus) ujung daun meruncing (acuminatus) dan pangkal daun runcing (acutus). Susunan daun tulang menyirip dan tulang daun menonjol ke permukaan bawah helai daun. Tepi daun rata, daging daun tipis tetapi kuat seperti perkamen (Karmawati dkk, 2010).

\subsection{Akar}

Akar kakao adalah akar tunggang. Pertumbuhan akar bisa sampai 8 meter kearah samping dan 15 ke arah bawah. Setelah dewasa tanaman tersebut akan menumbuhkan dua akar yang menyerupai akar tunggang (Siregar, 2000). Sistim perakaran kakao sangat berbeda tergantung dari keadaan tanah tempat tanaman tumbuh. Pada tanah-tanah yang permukaan air tanahnya dalam terutama pada lereng-lereng gunung, akar tunggang tumbuh panjang dan akar-akar lateral menembus sangat jauh ke dalam tanah. Sebaliknya pada tanah yang permukaan air tanahnya tinggi, akar tunggang tumbuh tidak begitu dalam dan akar lateral berkembang dekat permukaan tanah (Nasaruddin, 2004).

\subsection{Gambut}

Radjaguguk dan Setiadi (1991) menyebutkan gambut terdiri atas bahan organik yang kondisinya jenuh air, hasil dekomposisi dari bahan tanaman yang terjadi secara anaerob. Dalam Taksonomi Tanah USDA,(2010), tanah gambut disebut Histosols (histos $=$ tissue $=$ jaringan). Dengan ketebalan secara kumulatif minimal $40 \mathrm{~cm}$ atau $60 \mathrm{~cm}$ tergantung dari tingkat dekoposisi bahan gambut dan bobot jenisnya. Kementerian Kehutanan (2012) mendefinisikan "gambut" sebagai sisa bahan organik yang terakumulasi dalam jangka waktu yang panjang .

Penggunaan lahan gambut telah dimulai pada tahun 1900-an. Sejalan dengan 
pertambahan penduduk dan keterbatasan lahan pertanian menyebabkan pilihan diarahkan pada lahan gambut baik untuk kepentingan pertanian maupun untuk pemukiman penduduk. Lahan gambut merupakan suatu ekosistem khas dari segi struktur, fungsi, dan kerentanan. Pemanfaatan lahan gambut yang tidak bertanggung jawab akan menyebabkan kehilangan salah satu sumber daya yang berharga karena sifatnya yang tidak dapat diperbaharui (non-renewable). Seperti yang dilaporkan, di Kalimantan Tengah banyak dijumpai lahan bongkoryaitu lahan gambut yang terdegradasi (rusak) karena mengalami subsidensi dan dibiarkan atau ditinggalkan oleh pengelolanya. Lahan gambut memerlukan pengelolaan yang berbeda dengan lahan lain (Notohadiprawiro, 2006).

Lahan gambut apabila dikelola dengan baik, tetap dapat diusahakan sebagai lahan pertanian. Pengembangan pertanian pada lahan gambut harus mempertimbangkan sifat tanah gambut. Menurut Mawardi dkk, (2001), secara umum sifat kimia tanah gambut didominasi oleh asam-asam organik yang merupakan suatu hasil akumulasi sisa-sisa tanaman. Asam organik yang dihasilkan selama proses dekomposisi tersebut merupakan bahan yang bersifat toksit bagi tanaman, sehingga mengganggu proses metabolisme tanaman yang akan berakibat langsung terhadap produktifitasnya. Sementara itu secara fisik tanah gambut bersifat lebih berpori dibandingkan tanah mineral sehingga hal ini akan mengakibatkan cepatnya pergerakan air pada gambut yang belum terdekomposisi dengan sempurna sehingga jumlah air yang tersedia bagi tanaman sangat terbatas.

\subsection{Serbuk Gergaji}

Serbuk gergaji kayu merupakan limbah industri penggergajian kayu. Selama ini limbah serbuk kayu banyak menimbulkan masalah dalam penanganannya yang selama ini dibiarkan membusuk, ditumpuk, dan dibakar yang kesemuanya berdampan negatif terhadap lingkungan sehingga penanggulangannya perlu dipikirkan. Salah satu jalan yang dapat ditempuh adalah memanfaatkannya menjadi produk yang bernilai tambah dengan teknologi aplikatif dan kerakyatan sehingga hasilnya mudah disosialisasikan kepada masyarakat (Departmen Pertanian, 1970).

Media tanam bisa dibuat dengan dua cara, yaitu deng an menggunakan media dari serbuk gergaji kayu dan dengan menggunakan media potongan - potongan kecil dari kayu dengan bentuk silindris (lebih kecil dari ukuran lubang pengeboran). Serbuk gergaji dikeringkan dan diayak, kemudian dicampur dengan bahanbahan lainnya. Penambahan sukrose, sebaiknya dilarutkan dalam air dan disemprotkan kedalam bahan dan dibasahi. Serbuk gergaji digenggam tangan untuk mengetahui bahwa kadar airnya $65 \%$. Pelepasan serbuk dan terlihat pecah berantakan, berarti masih kering dan perlu ditambah air lagi. Genggaman dibuka dan serbuk bisa menggumpal berarti kadar airnya cukup, dan bila airnya menetes, berarti kadar airnya berlebihan. Bahan adukan tadi dimasukkan ke dalam kantong plastik tebal (polypropilene) atau ke dalam botol dan dipadatkan. Bagian atas kantong plastik diberi cincin dari bambu atau plastik tempat lubang untuk inokulasi. Lubang tersebut ditutup kapas dengan tambahan kertas penutup atau aluminium foil. Media serbuk disterilisasi pada autoklaf selama kurang lebih dua sampai dengan empat jam pada tekanan 1,5 atmosfir. Tahapan setelah diinokulasi, media serbuk diinkubasikan di dalam ruangan yang bersuhu kamar 24 o C 25 o C selama 30 s.d 40 hari. Kayu atau serbuk gergajian yang paling baik digunakan sebagai media tanam: kayu harus steril, yakni tidak mengandung pestisida atau bahan beracun lainnya (Departemen Pertanian, 1970)

\section{METODOLOGI PENELITIAN}

\subsection{Tempat dan Waktu}

Penelitian ini dilakukan di lahan percobaan Fakultas Pertanian Universitas Islam Indragiri, Tembilahan, mulai bulan April sampai dengan Juli 2019.

\subsection{Bahan dan alat}

Bahan yang digunakan dalam penelitian ini adalah benih kakao varietas Bundo-F1, polibag ukuran $25 \times 30 \mathrm{~cm}$, tanah gambut, serbuk gergaji, insektisida, serta bahanbahan lain yang mendukung dalam penelitian. Bahan dan Alat yang digunakan dalam penelitian ini adalah cangkul, bor, bak kecambah, timbangan, tanaman kakao, oven, gunting, cutter, parang, handsprayer, alat tulis, serta alat-alat lain yang mendukung dalam penelitian.

\subsection{Rancangan Penelitian}

Penelitian ini menggunakan Rancangan Acak Kelompok (RAK) nonfaktorial yang terdiri dari 6 perlakuan dengan 3 kali ulangan yaitu:

$\mathrm{M0}=$ gambut saja,

$M 1=1: 1$ (serbuk gergaji:gambut),

$M 2=2: 1$ (serbuk gergaji:gambut)

M3 = 3:1(serbuk gergaji:gambut 
Hasil penelitian dianalisis dengan menggunakan sidik ragam Turkey HSD taraf $5 \%$ berdasarkan model linier sebagai berikut: $Y i j=\mu+\mathrm{Ti}+\varepsilon i j$

Yij = Hasil pengamatan pada perlakuan ke-i dan ulangan ke-j

$\mu=$ rataan umum

$\mathrm{Ti}=$ pengaruh perlakuan ke-i

$\varepsilon \mathrm{ij}=$ pengaruh acak pada perlakuan ke-I ulangan ke-j

\subsection{Pelaksanaan Penelitian}

\subsubsection{Persiapan Lahan}

Persiapan dan pembersihan lahan terhadap berbagai jenis gulma dan sisa tanaman kemudian dikumpulkan menjadi satu lalu dibuang dan dibakar diluar lahan penelitian kemudian dilakukan pengolahan tanah tahap pertama.

\subsubsection{Pemasangan Label}

Label yang telah disiapkan dipasang sesuai dengan perlakuan masing-masing pada plot yang telah disiapkan kemudian disesuaikan dengan lay out penelitian di lapangan. Pemasangan label dilakukan satu hari sebelum pemberian perlakuan.

\subsubsection{Perlakuan}

\subsubsection{Pemberian serbuk gergaji}

Pemberian serbuk gergaji dilakukan pada saat satu minggu sebelum tanam diberikan sesuai dengan perlakuan masingmasing. Pemberian serbuk gergaji dilakukan satu kali

\subsubsection{Penanaman}

Benih benih kakao yang akan ditanaman sebelumnya diseleksi dengan cara merendam bibit sebelum penanaman, benih yang mengapung keatas tidak ditanam melainkan bibit yang tenggelam didalam air yang ditanam didalam polibag penelitian bertujan untuk megantisipasi benih yang tidak bagus

\subsection{Pemeliharaan}

\subsubsection{Penyiraman}

Penyiraman dilakukan dua kali dalam satu hari yaitu pada waktu pagi dan sore hari, jika turun hujan tidak dilakukan. Penyiraman bertujuan agar kelembaban tanah di sekitar daerah perakaran tetap terjaga dan penyiraman dilakukan dengan menggunakan gembor.

3.5.2. Pengendalian Hama dan Penyakit Pengendaian hama dan penyakit dilakukan dengan menyemprotkan fungisida Dithen M-45 dan insektisida furudan 3GR untuk pencegahan jamur dan serangga dilakukan seminggu setelah tanam. Dan dilakukan penyemprotan kembali jika ada serangan dari hama dan penyakit yang menyerang tanaman.

\subsection{Parameter Pengamatan}

Parameter yang diamati dalam penelitian ini antara lain:

\subsubsection{Tinggi Tanaman $(\mathrm{cm})$}

Pengukuran tinggi tanaman dilakukan pada akhir penelitian, pengukuran dari bagian pangkal batang (permukaan tanah) sampai ke titik tumbuh tanaman kakao. Pengukuran dengan menggunakan meteran. Data yang dihasilkan akan disajikan dalam bentuk tabel

\subsubsection{Diameter batang ( $\mathrm{mm})$}

Pengukuran diameter batang dilakukan pada akhir penelitian, yaitu dengan mengukur diameter batang dengan menggunakan jangka sorong. Data yang dihasilkan akan disajikan dalam bentuk tabel.

\subsection{3. jumlah daun(helai)}

Pertambahan jumlah daun dihitung dengan cara menghitung jumlah daun yang membuka sempurna. Pengamatan ini di lakukan diakhir penelitian pada tanaman sampel. Data yang di hasilkan akan disajikan dalam bentuk tabel.

\section{HASIL DAN PEMBAHASAN}

\subsection{Hasil dan pembahasan}

4.5.1. Tinggi tanaman $(\mathrm{cm})$

Hasil analisis sidik ragam (anova) terhadap tinggi tanaman Penggunaan limbah serbuk gergaji pada pembibitan Kakao (Theobroma cacao L.) menunjukkan bahwa perlakuan limbah serbuk gergaji berpengaruh nyata terhadap tinggi tanaman

Tabel : Tinggi tanaman Penggunaan Limbah Serbuk Gergaji pada Pembibitan Kakao (Theobroma cacao $L$ )

\begin{tabular}{ll}
\hline \multicolumn{1}{c}{ Perlakuan } & $\begin{array}{c}\text { Rerata } \\
\text { tinggi } \\
\text { tanaman } \\
(\mathrm{cm})\end{array}$ \\
\hline Gambut & $13,00 \mathrm{~d}$ \\
$1: 1$ (serbuk gergaji:gambut) & $15,00 \mathrm{c}$ \\
$2: 1$ (serbuk gergaji:gambut) & $18,00 \mathrm{~b}$ \\
$3: 1$ (serbuk gergaji:gambut) & $21,00 \mathrm{a}$ \\
\hline
\end{tabular}

$\mathrm{KK}=2,87 \%$

Keterangan : angka-angka yang diikuti huruf yang sama menyatakan tidak berbeda nyata pada uji beda nyata jujur tukey 0,05

Pada tabel diatas terlihat bahwa tinggi tanaman kakao pada penelitian ini berkisar antara 13,00-21,00 cm. Dalam perlakuan limbah serbuk gergaji, perlakuan pemberian limbah serbuk gergaji $3: 1$ (serbuk gergaji:gambut) memberikan nilai tinggi tanaman tertinggi yaitu $21,00 \mathrm{~cm}$. Tinggi tanaman kedua diperoleh pada perlakuan pemberian limbah serbuk gergaji 2:1 (serbuk 
gergaji:gambut) dengan nilai $18,00 \mathrm{~cm}$, tinggi tanaman tertinggi ketiga diperoleh pada perlakuan pemberian limbah serbuk gergaji 1:1 (serbuk gergaji:gambut) dengan nilai $15,00 \mathrm{~cm}$, dan tinggi tanaman terrendah diperoleh pada perlakuan gambut dengan nilai $13,00 \mathrm{~cm}$.

Tinggi tanaman dipengaruhi oleh intensitas cahaya. Intensitas cahaya yang tinggi menyebabkan tanaman pendek. Hal ini disebabkan auksin yang mempengaruhi pemanjangan sel bekerja lebih aktif dalam kondisi gelap. Tinggi tanaman merupakan usaha tanaman memperoleh cahaya (Gardner et al., 1991). Pertanian pada dasarnya merupakan sistem pemanfaatan energi cahaya matahari melalui proses fotosintesis. Apabila faktor genetik seragam, maka proses fotosintesis dipengaruhi oleh faktor lingkungan

\section{Selama} pertumbuhan

dan perkembangan tanaman akan membentuk bermacam-macam organ. Secara umum, organ tanaman terdiri dari organ vegetatif dan organ generatif. Akar, batang, dan daun dikelompokkan sebagai organ vegetatif; sedangkan bunga, buah, dan biji digolongkan sebagai organ generatif. Organ-organ vegetatif akan terbentuk lebih awal dibandingkan dengan organ-organ generatif. Fase dimana tanaman hanya membentuk organ-organ vegetatif disebut fase pertumbuhan vegetatif.

Pertumbuhan vegetatif dicirikan dengan berbagai aktivitas pertumbuhan dan perkembangan tanaman yang berhubungan dengan pembentukan dan pembesaran daun, pembentukan meristem apikal (tinggi tanaman) atau lateral dan pertumbuhannya menjadi cabang-cabang dan ekspansi system perakaran tanaman.

Harjadi (2009), menyatakan bahwa penetapan dosis pupuk yang tepat merupakan faktor penting dalam pemupukan, kemampuan tanaman dalam menyerap unsur hara akan menambah kekuatan bagi tanaman dan apabila unsur-unsur tersebut bekerja secara optimal maka akan menjadi lebih baik. Pusat Penelitian Kopi dan Kakao Indonesia (2004) yang menyatakan bahwa kadar hara makro dan mikro yang diperlukan tanaman harus dalam jumlah yangcukup serta variasi umur kakao menghendaki jenis dan jumlah hara yang berbeda untuk mendukungpertumbuhan dan produksi kakao

\subsubsection{Diameter batang $(\mathrm{mm})$}

Hasil analisis sidik ragam (anova) terhadap diameter batang Penggunaan limbah serbuk gergaji pada pembibitan Kakao (Theobroma cacao L.) menunjukkan bahwa perlakuan limbah serbuk gergaji berpengaruh nyata terhadap Diameter batang

Tabel : Diameter batang Penggunaan Limbah Serbuk Gergaji pada Pembibitan Kakao (Theobroma cacao $L$ )

Keterangan : angka-angka yang diikuti huruf yang sama menyatakan tidak berbeda nyata pada uji beda nyata jujur tukey 0,05

Pada tabel diatas terlihat bahwa

\begin{tabular}{ll}
\hline \multicolumn{1}{c}{ Perlakuan } & $\begin{array}{c}\text { Rerata } \\
\text { diameter } \\
\text { batang }\end{array}$ \\
\hline Gambut & $5,75 \mathrm{~d}$ \\
$1: 1$ (serbuk gergaji:gambut) & $6,00 \mathrm{c}$ \\
$2: 1$ (serbuk gergaji:gambut) & $6,32 \mathrm{~b}$ \\
$3: 1$ (serbuk gergaji:gambut) & $7,34 \mathrm{a}$ \\
\hline $\mathrm{KK}=1,98 \%$
\end{tabular}
$\mathrm{KK}=1,98 \%$ diameter batang tanaman kakao pada penelitian ini berkisar antara 5,75-7,34 mm. Dalam perlakuan limbah serbuk gergaji, perlakuan pemberian limbah serbuk gergaji 3:1 (serbuk gergaji:gambut) memberikan nilai diameter batang tertinggi yaitu 7,34 $\mathrm{mm}$. Diameter batang tanaman kedua diperoleh pada perlakuan pemberian limbah serbuk gergaji 2:1 (serbuk gergaji:gambut) dengan nilai $6,32 \mathrm{~mm}$, diameter batang tanaman tertinggi ketiga diperoleh pada perlakuan pemberian limbah serbuk gergaji $1: 1$ (serbuk gergaji:gambut) dengan nilai 6,00 $\mathrm{mm}$, dan diameter batang tanaman terrendah diperoleh pada perlakuan gambut dengan nilai $5,75 \mathrm{~mm}$.

Tumbuhan berkayu tumbuh menebal serta membentuk batang yang lebih padat akibat pertumbuhan xilem dan floem sekunder yang berkembang dari meristem sekunder. Penebalan batang dimulai setelah meristem apikal berkembang menjadi 3 lapis silinder jaringan, yaitu jaringan epidermis, jaringan dasar serta sistem vaskular. Penebalan organ ini disebut pertumbuhan sekunder.

Pertumbuhan sekunder melibatkan pembelahan sel pada 2 macam meristem yaitu kambium vaskular dan kambium gabus. Kambium vaskular mula-mula muncul dalam struktur silinder yang terdiri atas sel-sel yang aktif melakukan pembelahan yang disebut meristem lateral. Silinder ini berada diantara xilem dan floem primer. Pada gambar tersebut terlihat sektor batang pada saat permulaan pertumbuhan sekunder. Tingkat perkembangan batang pada saat ini sama dengan pada batang muda yang hanya mengalami pemanjangan akibat pertumbuhan primer, yang merupakan pembeda hanyalah keberadaan kambium vaskular. Kambium vaskular merupakan tipe 
meristem yang menarik, sebab dengan ketebalan hanya 1-2 lapis sel mampu membelah dalam 2 arah. Sel-sel yang dibentuk ke arah luar akan berkembang menjadi floem sekunder, sedangkan ke arah dalam dibentuk xilem sekunder. Kambium vaskular menghasilkan sel-sel xilem lebih banyak dari pada sel-sel floem.

Floem sekunder terdapat di sebelah luar kambium vaskular, sedangkan xilem sekunder terletak di sebelah dalam kambium tersebut. Dengan mengamati pertumbuhan xilem sekunder dapat diketahui penyebab utama peningkatan ketebalan batang. Terdapat 2 lapis xilem sekunder. Lapisan di sebelah dalam dihasilkan oleh kambium vaskular selama tahun pertama pertumbuhan sekunder, sedangkan lapisan xilem paling luar dibentuk pada tahun kedua pertumbuhan tersebut. Pertumbuhan yang menghasilkan lapisan xilem baru setiap tahun inilah yang menyebabkan penambahan ketebalan batang pada tumbuhan tahunan (perennial) dalam hal ini adalah tanaman sawit..

Xilem sekunder yang merupakan penyusun kayu pada pohon, semak, serta liana ini terdiri atas unsur trakea dan serat berdinding tebal yang kaya akan lignin. Dengan bertambahnya umur tumbuhan batang terus tumbuh menebal akibat aktivitas kambium vaskular yang menghasilkan selapis demi selapis xilem sekunder.

Lapisan-lapisan xilem sekunder yang dihasilkan setiap tahunnya pada akhirnya akan membentuk cincin-cincin pertumbuhan tahunan yang dikenal dengan lingkaran tahun. Lapisan-lapisan itu tampak menyerupai cincin yang terbentuk sebagai akibat aktivitas kambium yang tidak sama dalam setiap tahunnya. Pada tumbuhan berkayu yang hidup di daerah empat musim, kambium vaskular tidak aktif pada musim dingin, sehingga pembentukan xilem sekunder terhenti. Saat musim semi tiba, pertumbuhan dimulai kembali sehingga terbentuk silinder kayu musim semi. Kayu musim semi dicirikan dengan sel-sel yang berukuran besar dan berdinding tipis. Sel-sel xilem baru ini terbentuk paling awal dengan diikuti lapisan kayu yang terbentuk berikutnya, yaitu lapisan kayu musim panas. Setiap cincin pertumbuhan terdiri atas lapisan kayu musim semi yang dikelilingi oleh lapisan kayu musim panas. Cincin pertumbuhan sering digunakan untuk menduga umur pohon yaitu dengan menghitung jumlahnya yang tampak jelas pada potongan melintang batang kayu .

Kristanto (2013) yang menyatakan bahwa pada pembibitan kakao yang berumur
$<6$ bulan kebutuhan air per bibit tergantung pada kondisi kelembaban tanah yang dijadikan media tumbuh dalam pembibitan Mashur (2001) yang menyatakan bahwa vermikomposs merupakan bahan organik yang mengandung unsur hara utama N, P, K dan Mg. Selain diperkirakan mampu memperbaiki sifat fisik tanah, vermikompos diperkirakan mampu meningkatkan efisiensi pemupukan sehingga pupuk yang digunakan untuk pembibitan kakao dapat dikurangi.

Setyamidjaja (2009), menyatakan bahwa efisiensi pemupukan yang sesuai kebutuhan dapat dicapai apabila pupuk diberikan dalam jumlah yang sesuai kebutuhan tanaman, tidak terlalu banyak dan tidak terlalu sedikit. Budiana (2007), yang mengatakan bahwa dengan adanya nitrogen, daun akan menjalankan fungsinya dengan baik dalam proses fotosintesis. Hasil fotosintesis yang sempurna akan berpengaruh pada pertumbuhan daun, jumlah daun lebih banyak helaian lebar dan tampak mengkilap.

Lakitan (2007) faktor lingkungan yang mempengaruhi pertumbuhan dan perkembangan daun antara lain intensitas cahaya, suhu udara, ketersediaan air dan unsur hara. Krishamoorthi (2001), menjelaskan bahwa perpanjangan batang disebabkan oleh dua proses yaitu pembesaran dan pembelahan sel, sel membesar dan mencapai ukuran maksimal kemudian diikuti oleh pembelahan sel.

\subsubsection{Jumlah Daun (helai)}

Hasil analisis sidik ragam (anova) terhadap jumlah daun Penggunaan limbah serbuk gergaji pada pembibitan Kakao (Theobroma cacao L.) menunjukkan bahwa perlakuan limbah serbuk gergaji berpengaruh nyata terhadap jumlah daun

Tabel : Diameter batang Penggunaan Limbah Serbuk Gergaji pada Pembibitan Kakao (Theobroma cacao $L$ )

\begin{tabular}{lc}
\hline \multicolumn{1}{c}{ Perlakuan } & $\begin{array}{c}\text { Rerata } \\
\text { Jumlah } \\
\text { daun }\end{array}$ \\
\hline Gambut & $12,00 \mathrm{~d}$ \\
$1: 1$ (serbuk gergaji:gambut) & $14,56 \mathrm{c}$ \\
$2: 1$ (serbuk gergaji:gambut) & $16,28 \mathrm{~b}$ \\
$3: 1$ (serbuk gergaji:gambut) & $18,40 \mathrm{a}$ \\
\hline
\end{tabular}

\section{$\mathrm{KK}=4,87 \%$}

Keterangan : angka-angka yang diikuti huruf yang sama menyatakan tidak berbeda nyata pada uji beda nyata jujur tukey 0,05

Pada tabel diatas terlihat bahwa jumlah daun kakao pada penelitian ini berkisar antara 12,00 -18,40 helai. Dalam perlakuan limbah serbuk gergaji, perlakuan pemberian 
limbah serbuk gergaji $750 \mathrm{~g}$ serbuk gergaji/polibag memberikan nilai jumlah daun tertinggi yaitu 18,40 helai. Jumlah daun kedua diperoleh pada perlakuan pemberian limbah serbuk gergaji $500 \mathrm{~g}$ serbuk gergaji/polibag dengan nilai 16,28 helai, jumlah daun tertinggi ketiga diperoleh pada perlakuan pemberian limbah serbuk gergaji $250 \mathrm{~g}$ serbuk gergaji/polibag dengan nilai 14,56 helai, dan jumlah daun terrendah diperoleh pada perlakuan kontrol/tanpa limbah serbuk gergaji dengan nilai 12,00 helai.

Hal ini dijelaskan oleh Gardner et al (1991) bahwa jumlah bakal daun yang terdapat pada embrio biji yang masak merupakan karakteristik spesies. Jumlah dan ukuran daun dipengaruhi oleh genotipe dan lingkungan.

Daun merupakan organ utama tempat berlangsungnya fotosintesis. Oleh karena itu jumlah daun yang optimum memungkinkan distribusi (pembagian) cahaya antar daun lebih merata. Distribusi cahaya yang lebih merata antar daun mengurangi kejadian saling menaungi antar daun sehingga masing-masing daun dapat bekerja sebagaimana mestinya. Peningkatan intensitas cahaya (hingga tingkat optimum) meningkatkan laju asimilasi bersih total tanaman sehingga fotosintat yang terbentuk pun meningkat. Pembentukan fotosintat yang tinggi ini mendorong kecepatan pembentukan organ-organ tanaman seperti daun.

Faktor internal yang turut mempengaruhi laju fotosintesis daun adalah kandungan klorofil daun. Daun yang memiliki kandungan klorofil tinggi diharapkan lebih efisien dalam menangkap energi cahaya matahari untuk fotosintesis (Gardner et al., 1991).

Sari (2015), menunjukkan bahwa pertumbuhan jumlah daun yang menggunakan media serbuk gergaji dan tanah menjadi yang terendah pertumbuhannya dibanding media yang mengandung campuran tanah dengan sekam padi dan tanah dengan serabut kelapa, namun pertumbuhan pada media yang mengandung serbuk gergaji dan pada media tanah tidak berbeda. Pertumbuhan yang lambat pada media yang mengandung serbuk gergaji disebabkan yaitu saat pengomposan tidak seluruh komponen serbuk gergaji dirombak dengan sempurna sehingga ketersediaan unsur hara yang optimal tidak terpenuhi bagi tanaman. Diduga pertumbuhan jumlah daun pada media serbuk gergaji lebih baik dibanding media tanah diduga karena unsur hara yang terdapat pada media serbuk gergaji masih mampu mencukupi kebutuhan tanaman melalui larutan nutrisi yang sudah diberikan berupa $A B$ mix. Proses dekomposisi pada media serbuk gergaji yang melibatkan mikroba tidak berpengaruh terhadap ketersediaan hara.

Menurut Pratiwi (2019), lama pengomposan juga berpengaruh pada jumlah daun tanaman kubis bunga, hal ini berhubungan dengan waktu mikroba dalam melakukan dekomposisi. Selain itu perendaman dapat melarutkan tanin, sehingga tidak menghambat kerja enzim. Berkurangnya kadar tanin pada media serbuk gergaji dapat melalui perlakuan pencucian. Tanin memiliki sifat yang mudah larut dengan air. Tanin dapat mengikat selulosa, pektin, alkaloid dan menghambat kerja enzim karena daya ikatnya tersebut (Imelda 2015).

\section{KESIMPULAN DAN SARAN}

\subsection{Kesimpulan}

Seluruh pengujian parameter tersebut diatas menunjukan perlakuan limbah serbuk gergaji memberikan pengaruh nyata terhadap semua parameter dan dosis terbaik ada pada perlakuan 3:1 (serbuk gergaji:gambut)

\subsection{Saran}

Untuk penelitian selanjutnya di harapkan menggunakan bahan anorganik untuk melihat perbandingan hasil dengan bahan organik

\section{DAFTAR PUSTAKA}

[1] Budiana, N.S. 2007. Memupuk Tanaman Hias. Penebar Swadaya. Jakarta.

[2] Gardner. F.P.. R.B. Pearce. dan R.L. Mitchell. 1991. Physiology of Crop Plants (Fisiologi Tanaman Budidaya. alih bahasa oleh Susilo. H.). Universitas Indonesia Press. Jakarta. $428 \mathrm{p}$

[3] Harjadi, S.S. 2009. Pengantar Agronomi. PT.Gramedia Pustaka Utama, Jakarta.

[4] Imelda N, Periadnadi. 2015. Pengaruh Pencucian Media Serbuk Gergaji Terhadap Keberadaan dan Aktivitas Beberapa Enzim Media dan Tubuh Buah Jamur Tiram Putih. Jurnal of Natural Science 4(3): 310-321.

[5] Krisnamoorthi. 2001. Plant Growth Subtance. Tata Mc Grew Hill Publ. New Delhi.

[6] Kristanto, A. 2013. Panduan Budidaya Kakao. Pustaka Baru Press. Bandung.

[7] Lakitan, B. 2007. Dasar-Dasar Fisiologi Tumbuhan. Raja Grafindo Persada, Jakarta. 
[8] Mashur, 2001. Vermikompos (Kompos Cacing Tanah), Instalasi Penelitian dan Pengkajian Teknologi Pertanian (IPPTP), Mataram.

http://vermikompos.com/article/masnu r/vermikompos-kompos-cacing-tanah. (23 Mei 2011).

[9] Pratiwi SH, Purnamasari RT. 2019. Pengaruh Lama Pengomposan Serbuk Gergaji Kayu Jati dan Dosis EM4 Terhadap Pertumbuhan dan Hasil Tanaman Kubis Bunga (Brassica oleracea L.) Dataran Rendah. Buana Sains, 18(2): 139-148.

[10] Pusat Penelitian Kopi Kakao Indonesia (PPKKI). 2004. . Budidaya tanaman kakao. Agro Media Pustaka, Jakarta.

[11] Sari E, Fantashe D. 2015. Pengaruh Jenis Media Tanam Terhadap Pertumbuhan Vegetatif Tanaman Cabai Rawit (Capsicum frutescens L.). Bio-Lectura: Jurnal Pendidikan Biologi 2(2): 129-139.

[12] Setyamidjaja. $2009 . \quad$ Petunjuk Pemupukan. PT. Simpleks. Jakarta. 